\title{
Pathophysiology and management of combined aortic and mitral regurgitation
}

\section{Physiopathologie et prise en charge des insuffisances valvulaires aortiques et mitrales combinées}

\section{Philippe Unger ${ }^{a, *}$, Patrizio Lancellotti ${ }^{b, c}$, Mihaela Amzulescu ${ }^{a}$, Aurelia David-Cojocariu ${ }^{a}$, Didier de Cannière $^{\mathrm{d}}$}

\author{
a Department of Cardiology, CHU Saint-Pierre, Université Libre de Bruxelles, 1000 Brussels, \\ Belgium \\ b Department of Cardiology, Heart Valve Clinic, GIGA Cardiovascular Sciences, University of \\ Liège Hospital, CHU Sart Tilman, 4000 Liège, Belgium \\ c Gruppo Villa Maria Care and Research, Anthea Hospital, 70124 Bari, Italy \\ d Department of Surgery, CHU Saint-Pierre, Université Libre de Bruxelles, 1000 Brussels, \\ Belgium
}

Received 19 March 2019; received in revised form 7 April 2019; accepted 15 April 2019 Available online 29 May 2019

\section{KEYWORDS}

Aortic regurgitation; Mitral regurgitation; Multiple valve disease; Heart valve team

\begin{abstract}
Summary The combination of aortic and mitral regurgitation is a typical example of a frequent yet understudied multiple valve disease scenario. The aetiology is often rheumatic or degenerative; less frequently it can be induced by drugs or radiation, or caused by infective endocarditis or congenital valvular lesions. Aortic regurgitation resulting in secondary mitral regurgitation is also not uncommon. There are limited data to guide the management of combined aortic and mitral regurgitation. Left ventricular dysfunction is frequent at initial presentation, and even more so postoperatively, suggesting that surgical management should not be delayed, particularly when symptoms occur or when there is evidence of even subtle left ventricular dysfunction. The decision to operate on one or both valves not only depends on the severity of each lesion, but also on several other factors, including age, co-morbidities and frailty, the increased operative risk of double valve surgery, the increased risk of long-term
\end{abstract}

Abbreviations: AHA/ACC, American Heart Association/American College of Cardiology; AR, aortic regurgitation; LV, left ventricle/ventricular; MR, mitral regurgitation.

* Corresponding author at: Department of Cardiology, CHU Saint-Pierre, 322 rue Haute, 1000 Brussels, Belgium.

E-mail address: punger@ulb.ac.be (P. Unger). 
thrombotic and bleeding complications with multiple mechanical valves, the risk of leaving one valve unoperated and the probability of requiring redo surgery. The role of a multidisciplinary heart valve team is critical in this setting to optimize management and outcomes. The role of transcatheter approaches is currently limited, but technological advances will probably soon change the management paradigm.

(c) 2019 Elsevier Masson SAS. All rights reserved.

\author{
MOTS CLÉS \\ Insuffisance \\ aortique ; \\ Insuffisance mitrale ; \\ Cardiopathies \\ valvulaires ; \\ Affections valvulaires \\ multiples
}

\begin{abstract}
Résumé L'association d'une régurgitation valvulaire aortique à une régurgitation mitrale est un exemple typique d'affection plurivalvulaire, fréquente et cependant peu étudiée. Les étiologies rhumatismales et dégénératives sont les plus courantes ; l'endocardite infectieuse, les atteintes valvulaires médicamenteuses et radiques, ainsi que les valvulopathies congénitales devront aussi être recherchées. L'insuffisance aortique avec insuffisance mitrale secondaire est aussi une situation fréquente. La prise en charge des patients de ces patients n'a été que peu étudiée. La dysfonction systolique ventriculaire, fréquente lors du diagnostic, l'est encore plus en postopératoire, plaidant pour une prise en charge chirurgicale précoce, et ce, dès l'apparition de symptômes ou de signes > même discrets de dysfonction ventriculaire. La décision de traiter les deux valves d'emblée ou de n'en opérer qu'une dépendra non seulement de la sévérité de chacune des régurgitations, mais aussi de multiples facteurs, parmi lesquels l'âge, les comorbidités et la fragilité du patient, le risque opératoire et des risques hémorragiques et thrombotiques inhérents à la chirurgie bivalvulaire et le risque de laisser telle qu'elle une valve dysfonctionnelle et de devoir l'opérer ultérieurement. Une équipe multidisciplinaire spécialisée dans la prise en charge des affections valvulaires sera particulièrement bénéfique pour en optimaliser le traitement et améliorer le pronostic du patient. Si la place dévolue au traitement percutané des affections bivalvulaires régurgitantes est actuellement limitée, il ne fait aucun doute que les progrès technologiques modifieront considérablement notre approche thérapeutique.
\end{abstract}

(c) 2019 Elsevier Masson SAS. Tous droits réservés.

\section{Background}

The diagnosis of valvular heart disease has improved considerably over recent years, as has its management, but there are still limited data to guide clinical decision making in patients with multiple valve disease [1-3]. In this context, the combination of aortic regurgitation (AR) and mitral regurgitation (MR) is a typical example of a frequent yet understudied scenario [3]. The aim of this article is to provide a state-of-the-art review of the pathophysiology of this condition and management strategies, taking into account its various clinical presentations.

\section{Aetiology and prevalence}

With a reported prevalence in the CARDIA study of $0.5 \%$ in subjects aged 21 to 35 years, the combination of AR and MR is uncommon in young adults [4]. Among older patients with a mean age of 54 years from the Framingham cohort, the prevalence of regurgitation involving two valves was $10 \%$ for men and $8 \%$ for women, but more than mild MR and more than trace AR were infrequent [5]. However, Pai et al. reported that among patients with severe $A R$, up to onequarter also had moderate-to-severe MR [6]. In a Swedish nationwide registry including all hospitals and specialized outpatient clinics, $10.7 \%$ of patients with AR had concomitant MR, and $8 \%$ of patients with a diagnosis of MR had concomitant AR [7]. Moreover, $22 \%$ of the patients with multiple valve disease had a combination of $A R$ and MR, making this the third most frequent form of multiple and mixed valve disease [7].

In combined $A R$ and MR, the two conditions may have a similar aetiology or, less frequently, be the result of two unrelated primary disease processes. In the EuroHeart Survey, rheumatic heart disease was the leading cause of multiple valve disease ( $51 \%$ of cases) (Fig. 1), and degenerative aetiologies were responsible for $41 \%$ of cases [8]. However, whereas the incidence of rheumatic heart disease has declined over the past few decades, the aging of the population of industrialized countries accounts for a shift towards degenerative aetiologies, without a global reduction in the overall prevalence of valvular heart disease [9].

All other aetiologies, including infective endocarditis, drugs, radiation and congenital valvular lesions, are much less frequent. Nonetheless, multiple valve disease is observed in more than $20 \%$ of patients with drug- or radiation-induced heart valve disease $[10,11]$. Multiple valve disease resulting from infective endocarditis carries an increased risk of heart failure [12]. 

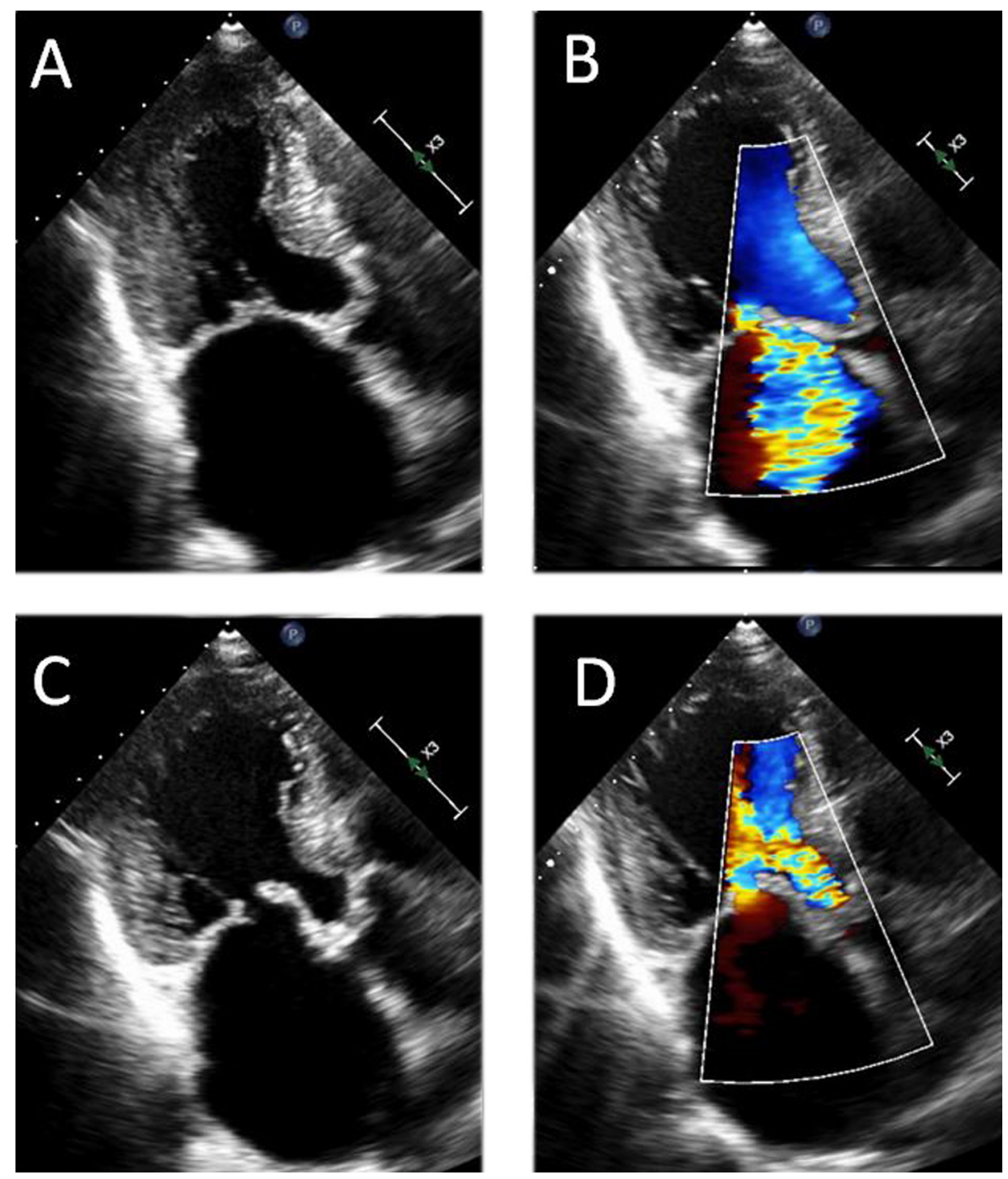

Figure 1. Combined rheumatic aortic and mitral regurgitation. A and B. Systolic still frames. C and D. Diastolic still frames.

Varying degrees of MR may result from remodelling, shape distortion and impaired function of the left ventricle (LV) associated with severe AR, thereby restricting mitral valve motion [13]. Secondary (functional) MR, in which the valve is structurally normal and the leaflet coaptation defect mainly results from ventricular and/or atrial remodelling, is common in patients with aortic valve disease; however, most studies included patients with aortic stenosis, and there are limited data focusing on patients with predominant AR $[13,14]$. In a series of 779 patients who had undergone aortic valve replacement, Lim et al. identified 155 patients (20\%) with mild-to-moderate functional MR, but the number of patients with severe MR was not reported [14]. In a series of 816 patients with AR, Beaudoin et al. reported a $5.6 \%$ prevalence of moderate or severe secondary MR [13]. Interestingly, the authors attributed this low prevalence to a significant increase in mitral valve leaflet area compared with controls and with patients with functional MR of other aetiologies [13]. The mechanism of this valvular remodelling was unclear, but it was postulated that the increase in mitral valve leaflet area might be a compensatory mechanism, preventing the development of MR by helping to preserve a normal relationship to the area needed for closure in a dilated LV [13].

\section{Pathophysiology}

Both $A R$ and MR increase left ventricular (LV) preload, whereas only AR has a significant effect on afterload, as a result of the impact of the increased total stroke volume ejected on systemic vascular resistance, and of the resulting systolic hypertension [15]. Therefore, severe LV dilatation may occur when AR and MR are present together. In addition, the resulting combination of volume and pressure load further increases wall thickness [16]. Thus, the resulting LV hypertrophy will usually be eccentric, with a wall thickness-to-cavity ratio typically $<0.45$, and increased sphericity [17]. At the onset of symptoms, patients may have a reduced $L V$ ejection fraction, which can be even worse than that associated with isolated AR or MR [17,18] (Fig. 2). 

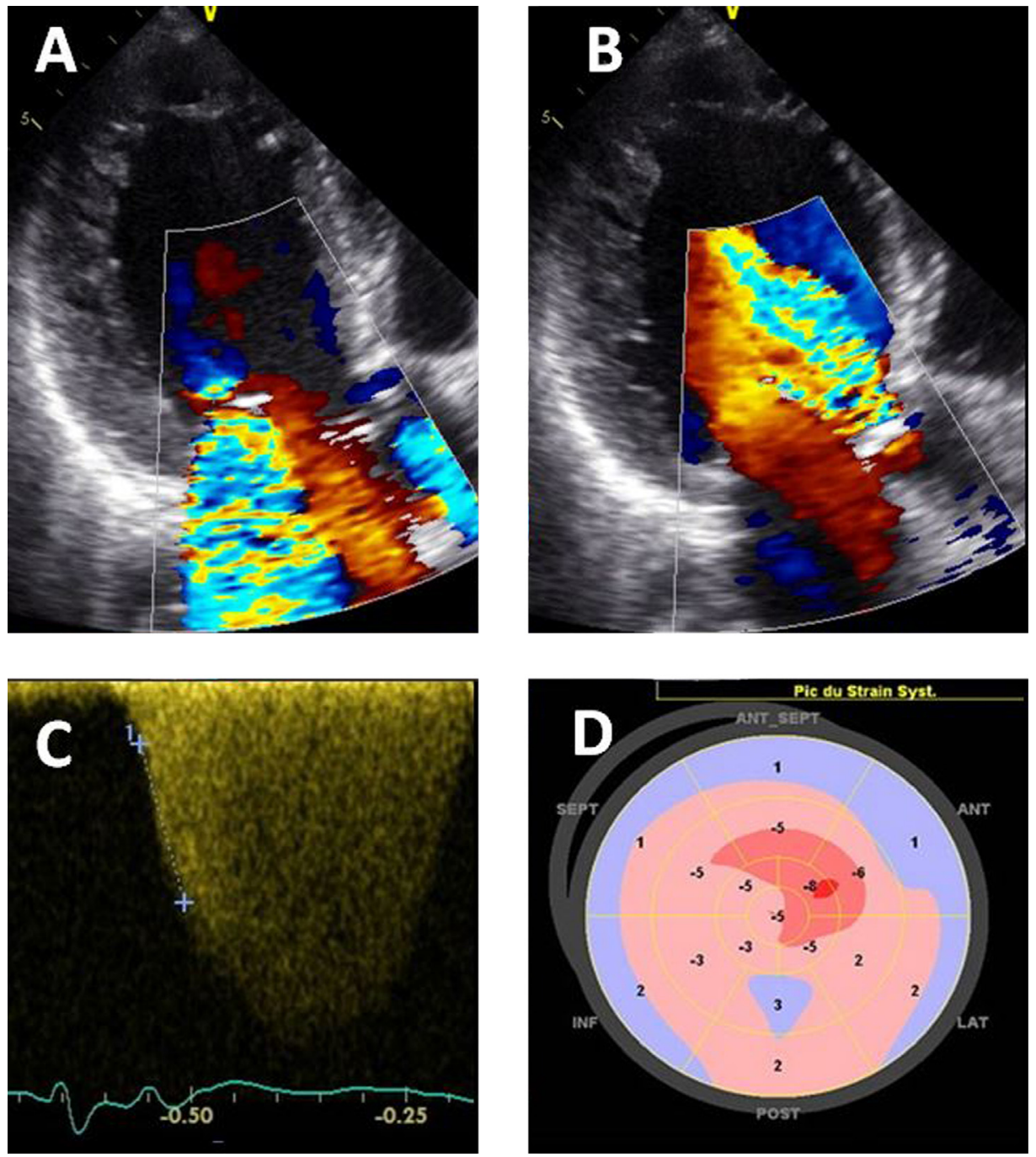

Figure 2. A. Severe mitral regurgitation. B. Severe aortic regurgitation. Left ventricular ejection fraction is $35 \%$ (not shown). C and D. Short dP/dt $(618 \mathrm{~ms} ; \mathrm{C})$ and marked reduction in global longitudinal strain (-6.4\%; D) are consistent with severe left ventricular dysfunction.

When acute and severe AR develops in patients with preexisting MR, the marked increase in LV end-diastolic pressure may be transmitted backwards, as premature mitral valve closure no longer limits the amount of flow into the left atrium and pulmonary veins (Fig. 3). The combination of $A R$ and MR predisposes to atrial fibrillation and pulmonary hypertension. As a result of chronic volume and pressure overload, MR is an independent risk factor for reduced survival in patients with severe $A R$, with mortality increasing with each grade of MR severity [6].

\section{Diagnosis}

The proximal isovelocity surface area (PISA) method and the assessment of vena contracta for quantifying regurgitant lesions are lesser load-dependent methods that can be useful in this setting. By contrast, volumetric methods of assessing the severity of MR and AR can be challenging, because left-sided assessment of forward flow is invalid. However, the right ventricular outflow tract can be used as an alternative to assess the net forward flow $[3,19]$. The pressure half-time can be inaccurate in assessing the severity of $A R$, and the mitral-to-aortic velocity time integral ratio is inherently unreliable. Cardiac magnetic resonance imaging may be used to quantify regurgitant lesions, particularly when the echocardiographic image quality is inadequate or when echocardiography variables are discordant with clinical assessment $[19,20]$. However, volumetric methods can also be inaccurate in the presence of multiple regurgitant lesions, as these methods assume that only one valve is affected [21]. Cardiac magnetic resonance imaging may accurately quantify changes in ventricular volumes, mass and function and, hence, by assessing the global burden of the valve regurgitations, may contribute to determining the optimal timing for intervention [20].

No study has evaluated the value of global longitudinal strain in the specific setting of multiple valve disease. However, its role has been consistently highlighted in isolated AR and MR $[22,23]$ and, consequently, it might be recommended for the detection of subclinical LV dysfunction. 

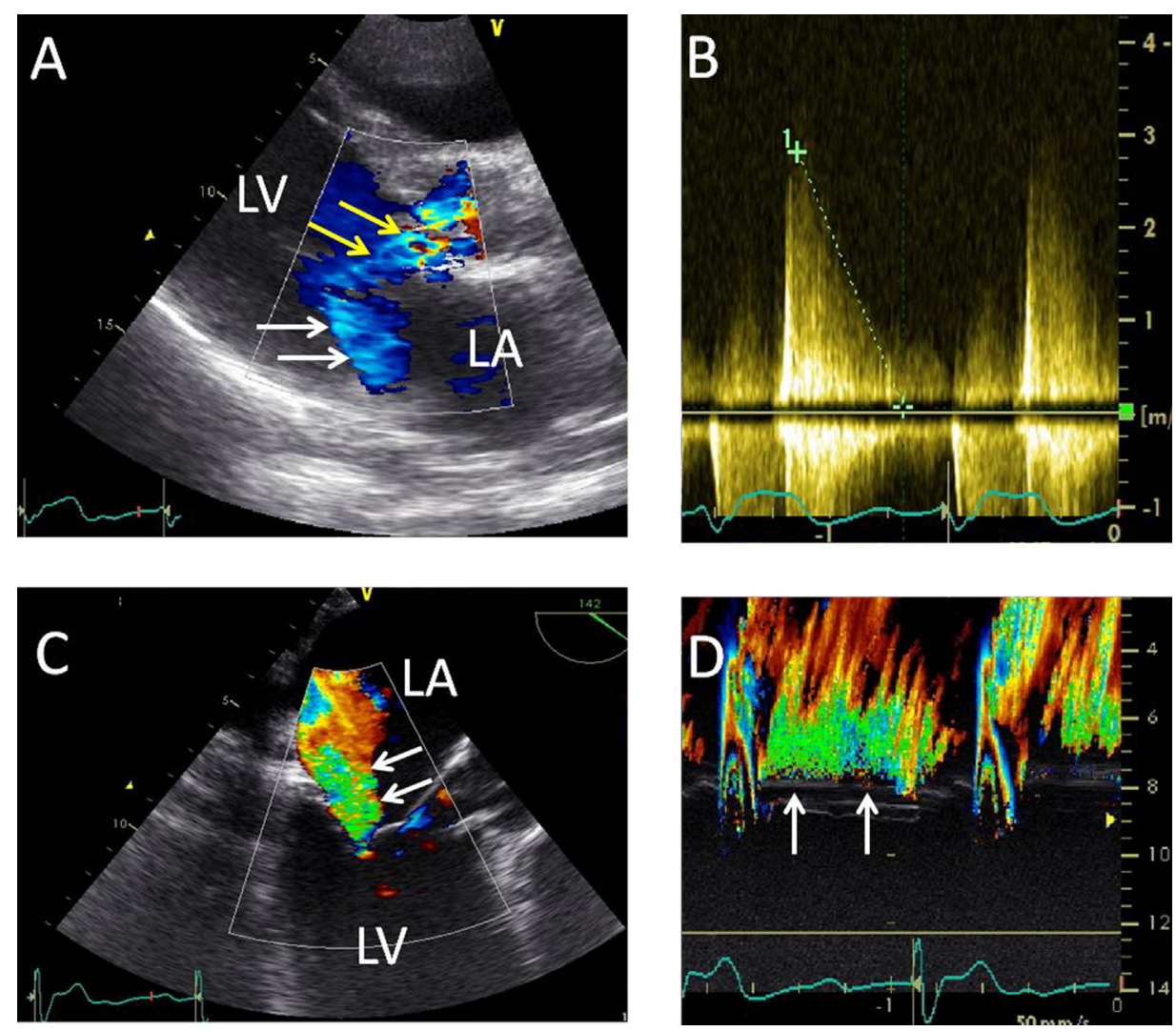

Figure 3. Acute aortic regurgitation (AR) as a result of infective endocarditis. A. Parasternal long-axis view showing concomitant AR (yellow arrows) and mitral regurgitation (MR) (white arrows) during end-diastole. B. The pressure half-time of the AR jet is $108 \mathrm{~ms}$, consistent with severe AR. C and D. Colour Doppler and colour M-mode obtained in the $140^{\circ}$ plane by transoesophageal echocardiography, confirming the occurrence of diastolic MR. Diastolic MR results from increased left ventricular diastolic pressure, and reflects premature mitral valve closure. LA: left atrium; LV: left ventricle.

\section{Management}

Most published results of double valve replacement for combined $A R$ and $M R$ come from studies focusing on young patients, predominantly with rheumatic heart disease aetiology $[17,18,22,24]$. Whether older patients with degenerative valve disease, and thus a longer history of valvular regurgitation and a lower life expectancy, would similarly benefit from extensive surgery is largely speculative. In general, the decision to operate on one or both valves depends on the severity of each lesion, but other factors should also be taken into account. The increased operative risk of double valve surgery $[25,26]$ and the increased risk of long-term thrombotic and bleeding complications with multiple mechanical valves [27] should be balanced against the probability of requiring redo surgery and its inherent risk if only one valve is replaced. This decision must therefore take into account many factors, including patient age, comorbidities and frailty [28]. In addition, expertise in cardiac imaging, cardiac surgery, haemodynamic management, geriatrics and anaesthesia, in the setting of a multidisciplinary heart valve team, is required to optimize management [28].

\section{Effects of aortic valve replacement on the severity of $M R$}

LV function, mass and volumes frequently improve following aortic valve replacement in patients undergoing surgery for severe AR, with a variable time-course response [29]. Thus, when concomitant functional MR is mild to moderate, aortic valve surgery for severe AR is expected to improve MR (Fig. 4). In a study by Lim et al., an improvement in MR severity was observed in $88 \%$ of patients, even without concomitant mitral valve annuloplasty, and was paralleled by a reduction in LV end-diastolic dimension [14]. However, whether correction of the volume overload by aortic valve replacement is sufficient to manage severe secondary MR has not yet been established.

\section{Effects of double valve surgery on LV volume and function}

As a result of specific loading conditions, LV function frequently decreases after mitral valve replacement for isolated $M R$, thereby precluding mitral valve surgery in patients with severe LV dysfunction. By contrast, LV function usually 

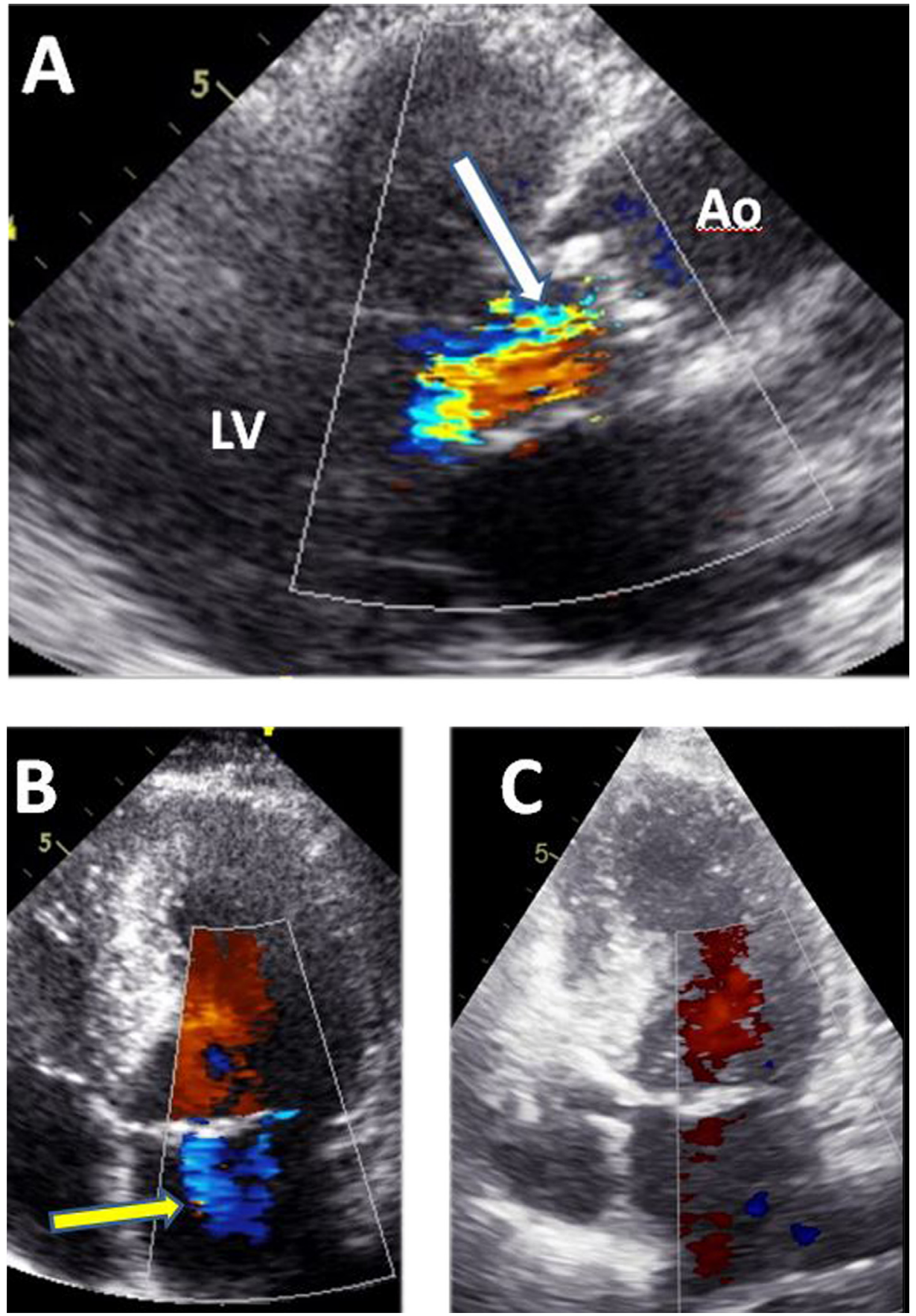

Figure 4. Severe aortic regurgitation. A. Using transoesophageal echocardiography, there is a large vena contracta, consistent with severe aortic regurgitation (white arrow). B. There is concomitant moderate secondary mitral regurgitation, as seen by transthoracic echocardiography (yellow arrow). C. Aortic valve replacement was performed; on the seventh postoperative day, only trace mitral regurgitation remained. Ao: ascending aorta; LV: left ventricle.

improves after aortic valve replacement for isolated AR, so the presence of even a severely depressed LV ejection fraction does not exclude aortic valve replacement. Whether double valve surgery for combined $A R$ and $M R$ improves or worsens LV performance is thus an important issue. Essop et al. compared the effects of double valve replacement for combined AR/MR with those of mitral valve replacement for isolated MR. A similar reduction in end-diastolic diameter was observed, but, 3 months after surgery, a larger reduction in end-systolic diameter after double valve surgery was associated with a smaller deterioration in ejection fraction [30]. This observation suggests that levels of ejection fraction that preclude surgery for isolated MR might still be acceptable for double valve replacement for AR/MR [30]. However, discrepant results were reported by Gentles et al. [17]. In a child and young adult population, the development or persistence of postoperative LV dysfunction (defined as a Z-score $<-2$ ) occurred significantly 

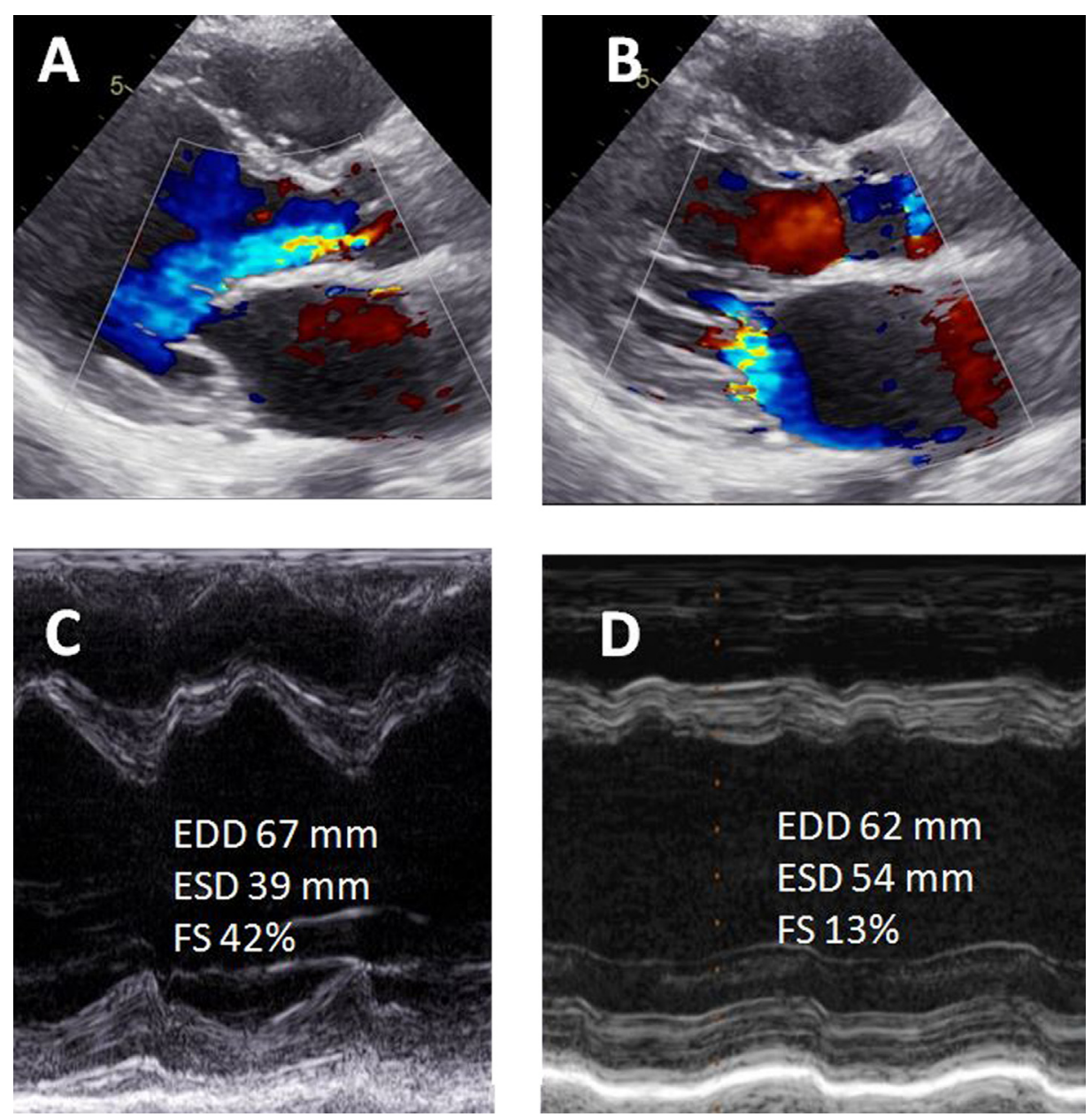

Figure 5. A. and B. Diastolic and systolic parasternal long-axis views showing severe AR and moderate-to-severe MR, respectively. C and D. Despite being preserved before surgery (C), fractional shortening is markedly decreased following double valve replacement (D). EDD: end-diastolic diameter; ESD: end-systolic diameter; FS: fractional shortening.

more often after double valve surgery (84.4\%) than after isolated aortic valve replacement for AR $(35.7 \%)$ or isolated mitral valve replacement for MR (57.1\%) [17] (Fig. 5). The better results from Essop et al. were attributed to a shorter duration of volume loading, thereby emphasizing the role of early surgical management [30]. Importantly, Skudicky et al. observed that, despite initial deterioration, LV ejection fraction tended to normalize 1 year after surgery [24]. Moreover, LV ejection fraction and end-systolic diameter were identified as independent predictive factors for postoperative systolic performance [24]. The probability of having an ejection fraction $<50 \%$ after a mean follow up of 40 months rose significantly when the preoperative ejection fraction was $<60 \%$, and/or when the LV end-systolic diameter was $>40 \mathrm{~mm}$ [24]. There is currently no definite lower threshold that would contraindicate a double valve procedure, particularly if $A R$ is predominant.

\section{Surgery and prognosis}

In a study dating back to the early 1990s, Niles et al. reported that patients with double valve replacement had significantly reduced postoperative survival, and more frequently reported persistent postoperative symptoms than patients who underwent surgery for single valve disease [18]. More recently, Pai et al. reported on a series of 191 patients with severe AR and concomitant grade 3-4+ MR. Among them, 65 patients underwent aortic valve replacement, and had significantly better survival than patients who did not have aortic valve replacement [6]. Importantly, among these patients, 39 had concomitant mitral valve surgery and 26 had only isolated aortic valve surgery. In this limited series, a survival benefit was observed only in the subgroup that had undergone mitral valve repair (17 patients). Similar benefits of mitral valve repair have been observed in retrospective series that included patients who had surgery for both AR and MR $[31,32]$, but studies have also been published in which no benefit of mitral repair over replacement was shown $[33,34]$. Prospective data addressing this issue are currently lacking. Combined aortic and mitral valve repair has occasionally been attempted, yielding acceptable long-term survival rates, but with the drawback of limited durability, leading to a 10-year reoperation rate of $35 \%$ [35]. 


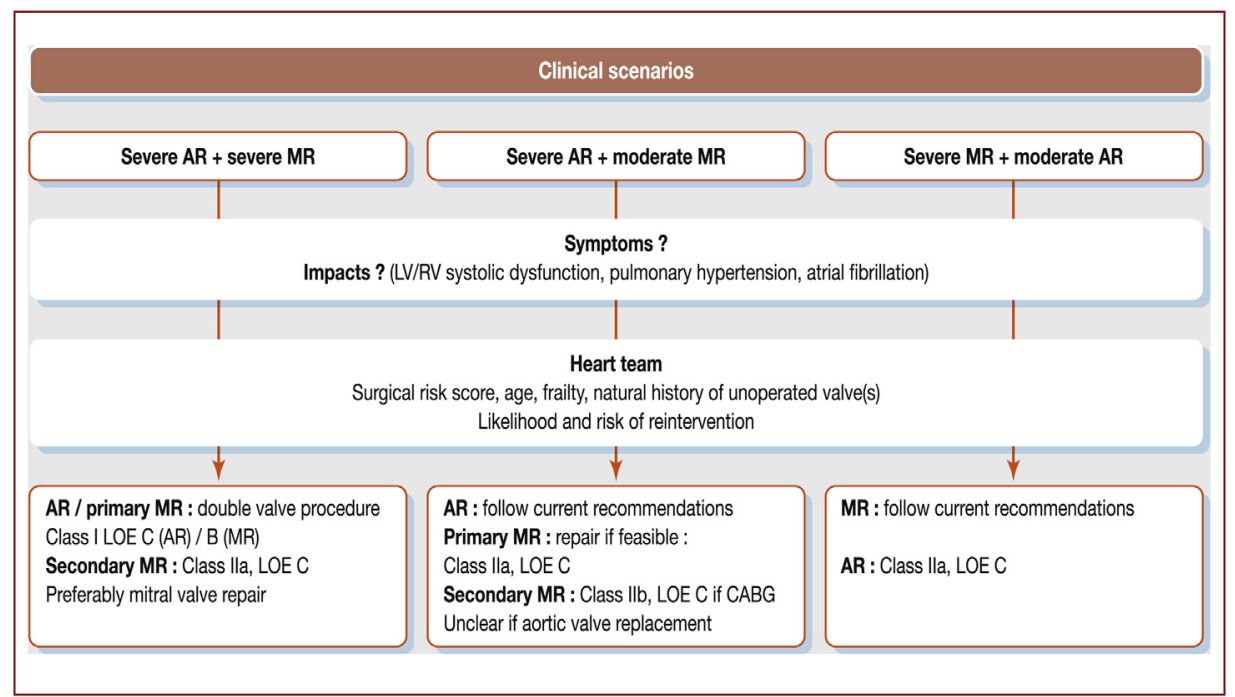

Figure 6. Management strategy according to the severity of aortic regurgitation (AR) and of mitral regurgitation (MR), according to the American Heart Association/American College of Cardiology guidelines for the management of patients with valvular heart disease [2]. CABG: coronary artery bypass grafting; LOE: level of evidence; LV: left ventricular; RV: right ventricular.

\section{Management according to lesion severity}

Current literature lacks evidence-based management strategies, as emphasized by the $C$ level of evidence supporting most recommendations in the current guidelines from Europe and the USA [1,2]. No medical treatment has proved beneficial for isolated or combined AR and MR. However, as is recommended in isolated $A R$, high blood pressure should be corrected using vasodilators, and diuretics may play an important role in reducing congestion and symptoms in patients with combined AR and MR for whom surgery is not feasible. Conventional heart failure treatments, including angiotensin-converting enzyme inhibitors, beta-blockers and mineralocorticoid receptors antagonists, should not be used in asymptomatic patients without LV dysfunction to avoid delay in symptom onset and, hence, in referral to surgery, but should be considered appropriate in patients not considered for surgery, or if symptoms and/or LV dysfunction persist or develop after surgery.

In clinical practice, the combination of AR and MR usually presents as one of the following scenarios: (1) the two regurgitations are severe; (2) AR is severe and MR is moderate; or (3) MR is severe and AR is moderate. Mild lesions need only watchful waiting. A management strategy adapted from current American Heart Association/American College of Cardiology (AHA/ACC) guidelines is presented in Fig. 6 [2].

\section{Scenario 1: The two lesions are severe}

In this setting, both lesions should be treated. Mitral valve repair or replacement in patients with chronic severe primary MR undergoing aortic valve replacement has received a Class I recommendation (level of evidence $B$ ), but has a Class Ila recommendation (level of evidence $C$ ) for secondary MR. Aortic valve replacement has a Class I recommendation (level of evidence $C$ ) for patients with severe AR while undergoing surgery for MR.

\section{Scenario 2: AR is severe and MR is moderate}

Severe AR should be managed according to current guidelines. However, whether moderate MR should be treated concomitantly remains controversial. Indeed, no survival benefit has been demonstrated after the surgical treatment of moderate secondary MR in prospective studies. Mitral valve repair in patients with moderate secondary MR undergoing coronary artery bypass surgery therefore has a Class Ilb recommendation (level of evidence $\mathrm{C}$ ) in current AHA/ACC guidelines. Moreover, the likelihood of MR improving following aortic valve replacement is high, making the need to treat MR in this setting even more questionable. Despite the lack of a randomized comparison between valve replacement and repair, it is widely accepted that, when feasible, valve repair is the preferred treatment for moderate primary MR. Therefore, concomitant mitral valve repair is considered reasonable in patients with chronic moderate primary MR undergoing cardiac surgery for other indications (Class Ila, level of evidence C).

\section{Scenario 3: MR is severe and AR is moderate}

Severe MR should be managed according to current guidelines. Correcting moderate AR at the time of mitral valve surgery is considered as reasonable in the AHA/ACC guidelines (Class Ila, level of evidence $C$ ), because of the likelihood of progressive worsening of AR over time.

Occasionally, two moderate lesions may have deleterious clinical repercussions, including symptoms, LV dilatation with or without dysfunction, reduction in net forward flow, increased natriuretic peptide concentrations and/or impaired exercise tolerance with maximal oxygen consumption (Fig. 7). To the best of our knowledge, no study has assessed the impact of combined moderate AR and moderate $M R$, and this scenario is not addressed in current guidelines. Nevertheless, such patients should undergo a thorough assessment of the global repercussions of the two regurgitant lesions. If the results are consistent with 

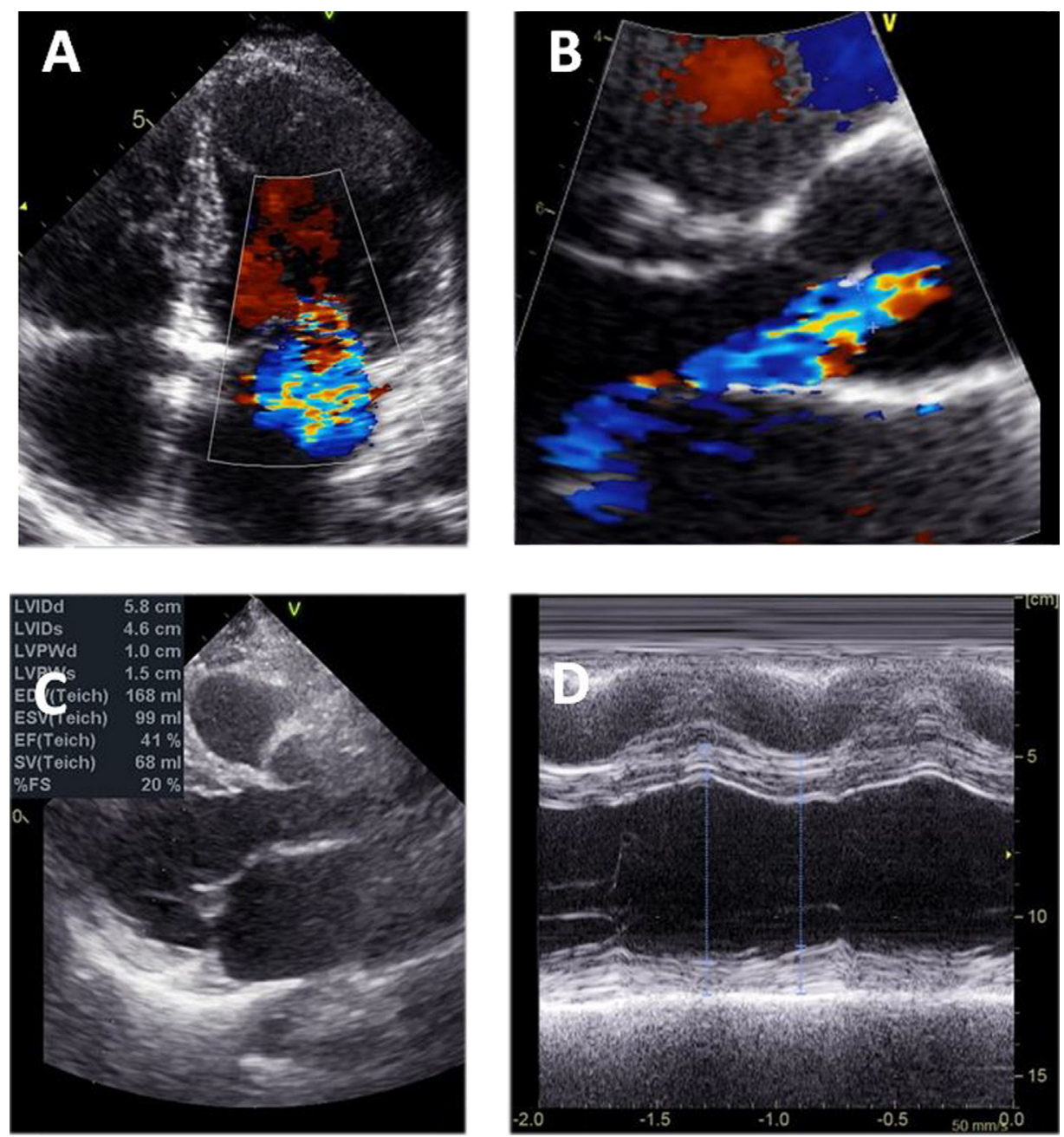

Figure 7. A and B. Rheumatic heart disease, including moderate mitral regurgitation (mitral effective regurgitant orifice $0.25 \mathrm{~cm}^{2}$; A) and moderate aortic regurgitation (vena contracta $5 \mathrm{~mm} ; \mathrm{B}$ ). C and D. Although each lesion is separately considered moderate, the left ventricle is mildly dilated (end-diastolic diameter $58 \mathrm{~mm}$ ), consistent with a significant global impact of the two regurgitations.

a significant global haemodynamic impact, valve repair or replacement might be considered, but this strategy requires careful exclusion of confounding factors, including chronic lung disease and primary ventricular dysfunction.

The management of asymptomatic patients in the setting of combined $A R$ and MR also lacks evidence-based support. If the two lesions are severe, the stricter thresholds of MR should be used to indicate surgery, including a LV end-systolic diameter $\geq 40 \mathrm{~mm}$ and/or a LV ejection fraction $<60 \%[1,24]$. If $M R$ or $A R$ is predominant, the respective thresholds in current guidelines should be used $[1,2]$, but even subtle evidence for LV dysfunction, including reduced global longitudinal strain, might be considered as an incentive for earlier surgery. As mentioned above, an assessment of the global repercussion should be strongly considered, including exercise testing to detect pseudoasymptomatic patients.

\section{Role of transcatheter interventions}

Percutaneous repair of MR has been shown to be safe and efficacious [36]. Although it has not yet become standard practice, there is recent evidence that transcatheter aortic valve replacement may be feasible in patients at high surgical risk with native valve AR [37]. However, the use of a fully transcatheter approach for the two conditions remains exceptional. In a recent literature review, Ando et al. identified 37 studies including 60 patients considered to be at high or inoperable surgical risk who had combined transcatheter aortic and mitral valve intervention. Among these, four patients $(7 \%)$ had both $A R$ and $M R$, three of whom had undergone at least one valve-in-valve procedure. Only one patient had a fully transcatheter approach performed on native valves $[38,39]$.

\section{Conclusions}

There are limited data to guide the management of combined $A R$ and MR. LV dysfunction is frequent at initial presentation and postoperative LV dysfunction is common, suggesting that surgical management should not be delayed, particularly when symptoms occur or when there is evidence of LV dysfunction. As with other combined valve disease 
combinations, all decisions should be made by a multidisciplinary heart team in order to optimize patient outcomes. The role of transcatheter approaches is currently limited, but technological advances will probably soon change the management paradigm.

\section{Disclosure of interest}

The authors declare that they have no competing interest.

\section{References}

[1] Baumgartner H, Falk V, Bax JJ, et al. 2017 ESC/EACTS Guidelines for the management of valvular heart disease. Eur Heart J 2017;38:2739-91.

[2] Nishimura RA, Otto CM, Bonow RO, et al. 2017 AHA/ACC focused update of the 2014 AHA/ACC guideline for the management of patients with valvular heart disease: a report of the American College of Cardiology/American Heart Association Task Force on clinical practice guidelines. Circulation 2017;135:e1159-95.

[3] Unger P, Pibarot P, Tribouilloy C, et al. Multiple and Mixed Valvular Heart Diseases. Circ Cardiovasc Imaging 2018;11:e007862.

[4] Reid CL, Anton-Culver H, Yunis C, Gardin JM. Prevalence and clinical correlates of isolated mitral, isolated aortic regurgitation, and both in adults aged 21 to 35 years (from the CARDIA study). Am J Cardiol 2007;99:830-4.

[5] Singh JP, Evans JC, Levy D, et al. Prevalence and clinical determinants of mitral, tricuspid, and aortic regurgitation (the Framingham Heart Study). Am J Cardiol 1999;83:897-902.

[6] Pai RG, Varadarajan P. Prognostic implications of mitral regurgitation in patients with severe aortic regurgitation. Circulation 2010;122:S43-7.

[7] Andell P, Li X, Martinsson A, et al. Epidemiology of valvular heart disease in a Swedish nationwide hospital-based register study. Heart 2017;103:1696-703.

[8] lung B, Baron G, Tornos P, Gohlke-Barwolf C, Butchart EG, Vahanian A. Valvular heart disease in the community: a European experience. Curr Probl Cardiol 2007;32:609-61.

[9] Goldbarg SH, Elmariah S, Miller MA, Fuster V. Insights into degenerative aortic valve disease. J Am Coll Cardiol 2007; 50:1205-13.

[10] Cutter DJ, Schaapveld M, Darby SC, et al. Risk of valvular heart disease after treatment for Hodgkin lymphoma. J Natl Cancer Inst 2015:107.

[11] Tribouilloy C, Marechaux S, Jobic Y, et al. Frequency of druginduced valvular heart disease in patients previously exposd to benfluorex: a multicentre prospective study. Eur Heart J 2013;34:3580-7.

[12] Lopez J, Revilla A, Vilacosta I, et al. Multiple-valve infective endocarditis: clinical, microbiologic, echocardiographic, and prognostic profile. Medicine (Baltimore) 2011;90:231-6.

[13] Beaudoin J, Handschumacher MD, Zeng X, et al. Mitral valve enlargement in chronic aortic regurgitation as a compensatory mechanism to prevent functional mitral regurgitation in the dilated left ventricle. J Am Coll Cardiol 2013;61:1809-16.

[14] Lim JY, Jung SH, Kim JB, et al. Management of concomitant mild to moderate functional mitral regurgitation during aortic valve surgery for severe aortic insufficiency. J Thorac Cardiovasc Surg 2014;148:441-6.

[15] Wisenbaugh T, Spann JF, Carabello BA. Differences in myocardial performance and load between patients with similar amounts of chronic aortic versus chronic mitral regurgitation. J Am Coll Cardiol 1984;3:916-23.
[16] Carabello BA. Is it ever too late to operate on the patient with valvular heart disease? J Am Coll Cardiol 2004;44:376-83.

[17] Gentles TL, Finucane AK, Remenyi B, Kerr AR, Wilson NJ. Ventricular function before and after surgery for isolated and combined regurgitation in the young. Ann Thorac Surg 2015;100:1383-9.

[18] Niles N, Borer JS, Kamen M, Hochreiter C, Devereux RB, Kligfield P. Preoperative left and right ventricular performance in combined aortic and mitral regurgitation and comparison with isolated aortic or mitral regurgitation. Am J Cardiol 1990;65:1372-8.

[19] Zoghbi WA, Adams D, Bonow RO, et al. Recommendations for noninvasive evaluation of native valvular regurgitation: a report from the american society of echocardiography developed in collaboration with the society for cardiovascular magnetic resonance. J Am Soc Echocardiogr 2017;30: $303-71$.

[20] Hundley WG, Bluemke DA, Finn JP, et al. ACCF/ACR/AHA/NASCI/SCMR 2010 expert consensus document on cardiovascular magnetic resonance: a report of the American College of Cardiology Foundation Task Force on Expert Consensus Documents. Circulation 2010;121: 2462-508.

[21] Cawley PJ, Maki JH, Otto CM. Cardiovascular magnetic resonance imaging for valvular heart disease: technique and validation. Circulation 2009;119:468-78.

[22] Alashi A, Mentias A, Abdallah A, et al. Incremental prognostic utility of left ventricular global longitudinal strain in asymptomatic patients with significant chronic aortic regurgitation and preserved left ventricular ejection fraction. JACC Cardiovasc Imaging 2018;11:673-82.

[23] Thomas JD, Kinno M. The Prognostic Role of Global Longitudinal Strain in Severe Primary Mitral Regurgitation: Moving Past the Proof-of-Concept Era. JACC Cardiovasc Imaging 2018;11:1245-7.

[24] Skudicky D, Essop MR, Sareli P. Time-related changes in left ventricular function after double valve replacement for combined aortic and mitral regurgitation in a young rheumatic population. Predictors of postoperative left ventricular performance and role of chordal preservation. Circulation 1997;95:899-904.

[25] lung B, Baron G, Butchart EG, et al. A prospective survey of patients with valvular heart disease in Europe: The Euro Heart Survey on Valvular Heart Disease. Eur Heart J 2003;24:1231-43.

[26] Vassileva CM, Li S, Thourani VH, et al. Outcome characteristics of multiple-valve surgery: comparison with single-valve procedures. Innovations (Phila) 2014;9:27-32.

[27] Cannegieter SC, Rosendaal FR, Wintzen AR, van der Meer FJ, Vandenbroucke JP, Briet E. Optimal oral anticoagulant therapy in patients with mechanical heart valves. N Engl J Med 1995;333:11-7.

[28] Unger P, Clavel MA, Lindman BR, Mathieu P, Pibarot P. Pathophysiology and management of multivalvular disease. Nat Rev Cardiol 2016;13:429-40.

[29] Une D, Mesana L, Chan V, et al. Clinical impact of changes in left ventricular function after aortic valve replacement: analysis from 3112 patients. Circulation 2015;132:741-7.

[30] Essop MR, Wisenbaugh TW, Sareli PE. Discordant changes in left ventricular performance after valve replacement for isolated rheumatic mitral regurgitation versus combined mitral and aortic regurgitation in teenagers. Am J Cardiol 1994;73: 910-4.

[31] Coutinho GF, Martinez Cereijo JM, Correia PM, et al. Longterm results after concomitant mitral and aortic valve surgery: repair or replacement? Eur J Cardiothorac Surg 2018;54:1085-92. 
[32] Gillinov AM, Blackstone EH, Cosgrove DM3rd, et al. Mitral valve repair with aortic valve replacement is superior to double valve replacement. J Thorac Cardiovasc Surg 2003;125:1372-87.

[33] Hamamoto M, Bando K, Kobayashi J, et al. Durability and outcome of aortic valve replacement with mitral valve repair versus double valve replacement. Ann Thorac Surg 2003;75:28-33 [discussion -4].

[34] Leavitt BJ, Baribeau YR, DiScipio AW, et al. Outcomes of patients undergoing concomitant aortic and mitral valve surgery in northern New England. Circulation 2009;120:S155-62.

[35] Gillinov AM, Blackstone EH, White J, et al. Durability of combined aortic and mitral valve repair. Ann Thorac Surg 2001;72:20-7.
[36] Lim GB. Benefit of the MitraClip for mitral regurgitation. Nat Rev Cardiol 2018;15:728.

[37] Haddad A, Arwani R, Altayar O, Sawas T, Murad MH, de Marchena E. Transcatheter aortic valve replacement in patients with pure native aortic valve regurgitation: A systematic review and meta-analysis. Clin Cardiol 2019;42:159-66.

[38] Ando T, Takagi H, Briasoulis A, et al. A systematic review of reported cases of combined transcatheter aortic and mitral valve interventions. Catheter Cardiovasc Interv 2018;91:124-34.

[39] Gerosa G, D’Onofrio A, Manzan E, et al. One-stage off-pump transapical mitral valve repair and aortic valve replacement. Circulation 2015;131:e430-4. 